\title{
Haematological Evaluation in Patients of Pancytopenia by Bone Marrow Aspiration
}

\author{
Pallavi Agrawal ${ }^{1}$, Yogesh Singh ${ }^{2}$, Nutan Agrawal ${ }^{3}$ \\ 1, 2 Department of Pathology, MLB Medical College, Jhansi, Uttarpradesh, India, \\ ${ }^{3}$ Department of Medicine, RMC Jalaun (Orai), Uttarpradesh, India.
}

\section{ABSTRACT}

\section{BACKGROUND}

Pancytopenia is a reduction in all three major series of formed elements of blood i.e. erythrocytes, leucocytes and platelets. Pancytopenia is not an uncommon condition encountered in day to day clinical practice. The underlying aetiology of pancytopenia determines the management and prognosis of patients. Bone marrow aspiration is a minimally invasive, out-patient procedure which provides definitive diagnosis in a case of pancytopenia. In developing countries like India, the causes of pancytopenia are not well defined, hence, we conducted this study in Bundelkhand region of India to evaluate causes of pancytopenia. We wanted to evaluate haematological findings in patients of pancytopenia, and to study bone marrow findings by bone marrow aspiration to understand the underlying aetiology of pancytopenia.

\section{METHODS}

This prospective study was conducted in the Department of Pathology at MLB Medical College, Jhansi, among 65 patients over a one and a half year period from March 2018 to September 2019, to evaluate the causes of pancytopenia.

\section{RESULTS}

We found that out of 65 cases, 32 cases were of megaloblastic anaemia (49.23\%), 20 cases were of dimorphic anaemia (30.77\%), 6 cases were of hypersplenism $(9.23 \%)$, 4 cases were of subleukemic leukemia (6.15\%), 2 cases of aplastic anaemia (3.7\%) and 1 case was of myelodysplastic syndrome (1.54\%).

\section{CONCLUSIONS}

Along with detailed clinical examination and complete blood count, bone marrow examination is indispensable to diagnose the aetiology of pancytopenia, thereby helping clinician in planning management of these patients.

\section{KEY WORDS}

Pancytopenia, Megaloblastic Anaemia, Dimorphic Anaemia, Bone Marrow Examination

\section{Corresponding Author:} Dr. Nutan Agrawal, PR-2, MLB Medical College Campus, Jhansi, Uttarpradesh, India.

E-mail: dr_nutan_agrawal@yahoo.com

DOI: $10.14260 / \mathrm{jemds} / 2021 / 295$

How to Cite This Article:

Agrawal $P$, Singh $Y$, Agrawal $N$. Haematological evaluation in patients of pancytopenia by bone marrow aspiration. J Evolution Med Dent Sci 2021;10(19):13981402, DOI: $10.14260 /$ jemds/2021/295

Submission 11-07-2020,

Peer Review 14-01-2021,

Acceptance 20-01-2021,

Published 10-05-2021.

Copyright (c) 2021 JEMDS. This is an open access article distributed under Creative Commons Attribution License [Attribution 4.0 International (CC BY 4.0)] 


\section{BACKGROUND}

Pancytopenia is a reduction in all three major formed elements of the blood i.e. erythrocytes, leucocytes and platelets. It is not a disease entity, but a triad of findings that may result from a number of disease processes. Pancytopenia is a commonly encountered condition in day to day clinical practice in Bundelkhand region. It can be a manifestation of some trivial treatable cause to life threatening malignant disorders both hematological as well as non hematological. The underlying conditions may vary from megaloblastic bone marrow to hypersplenism to Myelodysblastic symdrome (MDS) to acute leukemias to aplastic anaemia etc.

Various mechanisms can be responsible for development of Pancytopenia like ineffective hematopoiesis with cell death in the bone marrow and formation of defective cells that are rapidly removed from the circulation via sequestration or destruction of cells by the action of antibodies and trapping of normal cells in hypertrophied and overactive reticuloendothelial system or decrease in hematopoietic cell production, as a result of destruction of marrow by toxins or suppression of normal marrow growth and differentiation. Manifestations of peripheral pancytopenia are due to a wide variety of disorders which primarily or secondarily affect the bone marrow. The presenting symptoms are usually attributable to anaemia, thrombocytopenia and rarely to leucopoenia. Pancytopenia should be suspected on clinical grounds when a patient presents with unexplained weakness and low grade fever. The aetiology of pancytopenia varies in different populations depending on the differences in age patterns, nutritional status, climate and the prevalence of infections. In developing countries like India, the causes of pancytopenia are not well defined. ${ }^{1}$ Our MLB Medical College, Jhansi is a tertiary care centre and it drains whole of Bundelkhand region. But, only few studies have been conducted in Bundelkhand region to evaluate this important entity.

So, the present study was conducted to evaluate the causes of pancytopenia in this region. Also, Bundelkhand region, being economically backward, nutritional deficiencies like megaloblastic anaemia (Vitamin B12 and Folic Acid deficiency) and dimorphic anaemia (combined Vitamin B12 and Iron Deficiency) are quite common and it is well known that megaloblastic anaemia is an important cause of pancytopenia.

\section{METHODS}

This cross-sectional study was conducted in the Department of Pathology at MLB Medical College, Jhansi on 65 patients attending Indoor and Outpatient department of Maharani Laxmi Bai Medical College \& associated Hospital, Jhansi, from March 2018 to September 2019, to evaluate the causes of pancytopenia. The sample size was decided on the basis of clinical judgement. The study was approved by ethics committee and informed consent was obtained.

\section{Inclusion Criteria}

- $\quad$ Age above 1 years and below 90 years.
- Only the patients with Pancytopenia \{includes anaemia $(\mathrm{Hb}<9 \mathrm{gm} / \mathrm{dl}$ ), Leucopenia (TLC $<4000 / \mathrm{cu} \mathrm{mm}$ ) and thrombocytopenia (Platelet count < l lakh / cu mm) $\}$ or Bicytopenia \{anaemia $(\mathrm{Hb}<9 \mathrm{gm} / \mathrm{dl})$ and leucopenia (TLC $<4000$ / cu mm) $\}$ were included in the study.

- Patients who gave informed consent.

\section{Exclusion Criteria}

Following patients were excluded from the study.

1. Infants (age $<1$ years) and patients $>90$ years of age.

2. All pregnant females.

3. Any patients with any other contraindication for bone marrow aspiration like-

- Haemorrhagic disorders such as haemophilia and concomitant use of anticoagulants.

- Skin infection or recent radiation therapy at sampling site.

- Bone disorders such as osteoporosis, osteomyelitis or osteogenesis imperfecta.

4. All the patients who refused to give informed consent.

Then, all the patients who were included in this study were subjected to clinical examination and blood investigations. General blood picture examination, reticulocyte count and bone marrow aspiration of all study subjects were done.

\section{Statistical Analysis}

SPSS (Statistical Package for Social Sciences) version 22.0 and Graph Pad (online) for windows was used for data analysis. Frequency, cumulative percent, mean and standard deviation were calculated. Tables and typed materials were designed by Microsoft Office Word / Excel 2007 / 10.

\section{RESULTS}

We conducted the present prospective study on 65 patients with a diagnosis of Pancytopenia at the Department of Pathology, MLBMC, Jhansi from March 2018 to September 2019. The following data was recorded and analysed -

\begin{tabular}{|ccccc|}
\hline Age Group (Yrs) & Male & Female & Total No. of Cases & Percentage \\
$2-20$ & 12 & 9 & 21 & $32.31 \%$ \\
$21-40$ & 16 & 15 & 31 & $47.69 \%$ \\
$41-60$ & 07 & 02 & 09 & $13.85 \%$ \\
$61-80$ & 03 & 01 & 04 & $6.15 \%$ \\
$>80$ & 0 & 0 & 0 & $0 \%$ \\
Total & $\mathbf{3 8}$ & $\mathbf{2 7}$ & $\mathbf{6 5}$ & \\
Mean \pm SD for age & \multicolumn{5}{|c}{$31.77 \pm 15.27$ yrs } \\
\hline Table 1. Age and Sex Distribution of Patients with Pancytopenia \\
\hline
\end{tabular}

Mean \pm SD for age was found to be $31.77 \pm 15.27$ yrs. Most of the patients were in the age group of $21-40$ years $(47.69$ $\%)$. The sex distribution of cases of pancytopenia showed a mild male preponderance. The male to female ratio was 1.4:1. The mean \pm SD of the haemoglobin was found to be $5.54 \pm 1.52$ $\mathrm{g} / \mathrm{dl}$. The minimum haemoglobin was found to be $2.3 \mathrm{gm} / \mathrm{dl}$ and maximum was $8.9 \mathrm{gm} / \mathrm{dl}$.

Majority (50.77\%) of the patients had hemoglobin ranging from $3.1-5 \mathrm{~g} / \mathrm{dl}$. Two (3.08 \%) of the patients had haemoglobin values between 1 to $3 \mathrm{gm} / \mathrm{dl}$. 


\begin{tabular}{|c|c|c|c|}
\hline \multirow{7}{*}{$\begin{array}{c}\text { Range of } \\
\text { haemoglobin in } \\
\text { patients with } \\
\text { pancytopenia }\end{array}$} & $\begin{array}{l}\text { Haemoglobin } \\
\text { Percentage }\end{array}$ & No. of Cases & Percentage \\
\hline & 1 to 3 & 2 & $3.08 \%$ \\
\hline & 3.1 to 5 & 33 & $50.77 \%$ \\
\hline & 5.1 to 7 & 23 & $35.38 \%$ \\
\hline & 7.1 to 9 & 7 & $10.77 \%$ \\
\hline & Total & 65 & $100 \%$ \\
\hline & Mean \pm SD & \multicolumn{2}{|c|}{$5.54 \pm 1.52 \mathrm{~g} / \mathrm{dl}$} \\
\hline \multirow{7}{*}{$\begin{array}{c}\text { Range of leukocyte } \\
\text { count in patients } \\
\text { with pancytopenia }\end{array}$} & $\begin{array}{l}\text { leukocyte count } \\
\text { (cells / cumm) }\end{array}$ & No. of cases & Percentage \\
\hline & $500-1000$ & 6 & $9.23 \%$ \\
\hline & $1100-2000$ & 13 & $20.00 \%$ \\
\hline & $2100-3000$ & 26 & $40.00 \%$ \\
\hline & $3100-4000$ & 20 & $30.77 \%$ \\
\hline & Total & 65 & $100 \%$ \\
\hline & Mean \pm SD & \multicolumn{2}{|c|}{$2669.35 \pm 890.59 /$ cu mm } \\
\hline \multirow{7}{*}{$\begin{array}{l}\text { Range of platelet } \\
\text { count in patients } \\
\text { with pancytopenia }\end{array}$} & $\begin{array}{l}\text { Platelet count (cells } \\
\qquad / \text { cu mm) }\end{array}$ & No. of cases & Percentage \\
\hline & $4000-25000$ & 5 & $7.69 \%$ \\
\hline & $26000-50000$ & 23 & $35.38 \%$ \\
\hline & $51000-75000$ & 13 & $20.00 \%$ \\
\hline & $76000-100000$ & 24 & $36.92 \%$ \\
\hline & Total & 65 & 100 \\
\hline & Mean \pm SD & \multicolumn{2}{|c|}{$63048.39 \pm 24114.23$ / cu mm } \\
\hline \multirow{6}{*}{$\begin{array}{c}\text { Range of } \\
\text { reticulocyte count } \\
\text { in patients with } \\
\text { pancytopenia }\end{array}$} & $\begin{array}{l}\text { Reticulocyte count } \\
(\%)\end{array}$ & No. of cases & Percentage \\
\hline & $<0.5$ & 2 & $3.08 \%$ \\
\hline & to 2.5 & 58 & $89.23 \%$ \\
\hline & $>2.5$ & 5 & $7.69 \%$ \\
\hline & Total & 65 & 100 \\
\hline & Mean \pm SD & \multicolumn{2}{|c|}{$1.33 \pm 0.96$} \\
\hline \multicolumn{4}{|c|}{$\begin{array}{l}\text { Table 2. Range of Hemoglobin, Leukocyte Count, Platelet Count and } \\
\text { Reticulocyte Count in Patients with Pancytopenia }\end{array}$} \\
\hline
\end{tabular}

The mean of the TLC was found to be 2669.35 / cu mm. The total leukocyte count was in the range of $500-4000$ cells / cu $\mathrm{mm}$. Most $(40 \%)$ of the patients had values in the range of $2100-3000$ cells / cumm. Six (9.23\%) of the patients had values in between 500 and 1000 cells / cu mm. The mean of the platelet count was found to be 63048.39 / cu mm. The range of platelet count varied from $4000-1,00,000$ cells / cu $\mathrm{mm}$. Most (36.92\%) patients had platelet counts in the range of 76,000 - 10,0000 cells / cu mm. The mean of the reticulocyte count was found to be 1.33. The reticulocyte count varied from $>0.5->2.5 \%$. Majority (89.23\%) of the patients had reticulocyte count in the range of $0.5-2.5 \%, 3.08 \%$ of them had values $<0.5$. The most common findings on physical examination were splenomegaly $(47.69 \%)$ followed by hepatomegaly (32.31\%).

\begin{tabular}{|ccc|c|}
\hline Sl. No. & Clinical Feature & No. of Patients & Percentage (\%) \\
\hline 1. & Weakness & 46 & $70.76 \%$ \\
2. & Dyspnoea & 7 & $10.76 \%$ \\
3. & Dizziness & 10 & $15.38 \%$ \\
4. & Pallor & 65 & $100 \%$ \\
5. & Icterus & 15 & $23.07 \%$ \\
6. & Hepatomegaly & 21 & $32.30 \%$ \\
\hline 7. & Splenomegaly & 31 & $47.69 \%$ \\
\hline \multicolumn{3}{|c|}{ Table 3. Clinical Presentation } \\
\hline
\end{tabular}

\section{General Blood Picture (GBP)}

The sex distribution of cases of pancytopenia showed a mild male preponderance. On the contrary, there was a female predominance in dimorphic anaemia and the female to male ratio was found to be 1.5:1, which was shown by the higher prevalence of iron deficiency anaemia among females.

We found that out of 65 cases, majority of the cases (32) were of Megaloblastic anaemia(49.23\%) followed by 20 cases Dimorphic anaemias (30.77\%), 6 cases of Hypersplenism (9.23\%), 4 cases were of Subleukemic Leukemia (6.15\%), 2 cases of Aplastic anaemia (3.7\%) and 1 case of MDS (1.54\%).

\begin{tabular}{|cccc|}
\hline Sl. No. & Type of Anaemia on GBP & No. of Patients & Percentage (\%) \\
1. & Macrocytic anaemia & 32 & $49.23 \%$ \\
2. & Microcytic anaemia & 6 & $9.23 \%$ \\
3. & Dimorphic anaemia & 20 & $30.77 \%$ \\
4. & Normocytic anaemia & 6 & $9.23 \%$ \\
Total & $\mathbf{6 5}$ \\
\hline \multicolumn{3}{|c|}{ Table 4. Distribution of Morphological Type of Anaemia } \\
Based on General Blood Picture \\
\hline
\end{tabular}

\begin{tabular}{|c|c|c|c|}
\hline Sl.No & Diagnosis on BMA & No. of Cases & Percentage \\
\hline 1 & Megaloblastic anaemia & 32 & $49.23 \%$ \\
\hline 2 & Dimorphic anaemia & 20 & $30.77 \%$ \\
\hline 3 & Hypersplenism & 6 & $9.23 \%$ \\
\hline 4 & Subleukemic leukaemia & 4 & $6.15 \%$ \\
\hline 5 & Aplastic anaemia & 2 & $3.08 \%$ \\
\hline 6 & MDS & 1 & $1.54 \%$ \\
\hline & Total & 65 & $100 \%$ \\
\hline \multicolumn{4}{|c|}{$\begin{array}{c}\text { Table 5. Distribution of Causes of Pancytopenia } \\
\text { by Bone Marrow Aspiration }\end{array}$} \\
\hline
\end{tabular}
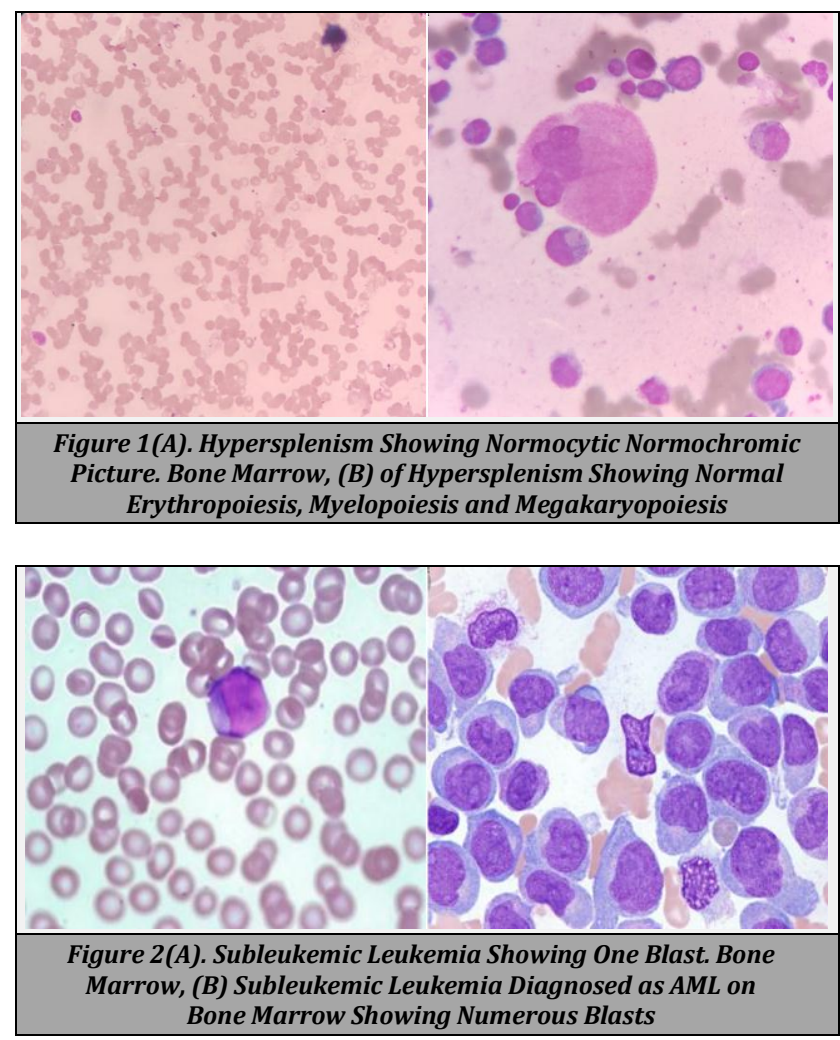

\section{DISCUSSION}

To evaluate the cause of pancytopenia, careful assessment of the blood film is important apart from clinical history and examination. Bone marrow examination is an indispensable diagnostic procedure to confirm the diagnosis and thereby finding the aetiology of pancytopenia.

In the present study also, megaloblastic anaemia was found to be the underlying cause of pancytopenia in 32 (49.23 $\%$ ) out of 65 cases, making it the most common aetiology of pancytopenia in Bundelkhand region.

The second most common cause in our study was found to be dimorphic anaemia accounting for 20 (30.77\%) out of 65 cases, followed by hypersplenism which accounted for $6(9.23$ $\%)$ cases out of 65 cases, 4 (6.15\%) cases of sub leukemic leukaemia, 2 (3.07\%) cases of aplastic anaemia and 1 case of MDS. 
Various factors like geographic distribution, nutritional status, genetic factors etc. may cause variation in the incidence of disorders which cause pancytopenia. ${ }^{2}$ Bundelkhand region is an economically and socially backward region, hence the prevalence of nutritional deficiency anaemias is very common. The prevalence of Megaloblastic anaemia due to vitamin B12 and folic acid deficiencies are also quite common after iron deficiency anaemia. The combined deficiency of vitamin B12 and iron (which presents as Dimorphic picture) is also quite prevalent specially among females because of lack of proper nutrition. Hypersplenism was found to be the third most common cause of pancytopenia in our study. The high prevalence of tropical splenomegaly especially due to malarial endemicity $^{3}$ in Bundelkhand region explains why hypersplenism comes just next to megaloblastic anaemia and dimorphic anaemia as cause of pancytopenia in this region.

Similar results were observed by Tilak V. et al. (1998) in a study on 77 patients who found megaloblastic anaemia to be the most common cause of pancytopenia ( $68 \%$ ), although the second most common cause in their study was aplastic anaemia $(7.7 \%) .^{2}$ In a similar study conducted by Khodke et al., (2000) on 50 patients of pancytopenia, megaloblastic anaemia was found to be the most common cause (44\%), which was quite comparable to our study (49\%). However, second most common cause in their study was aplastic anaemia (14 \%). ${ }^{4}$ In another study by Fahim Manzoor et al., (2014), conducted on 50 cases of pancytopenia, Megaloblastic anaemia due to Vitamin B12 or Folate deficiency was found to be the most common cause, ${ }^{4}$ which is similar to the present study. But the second most common cause in their study was found to be hypoplastic / aplastic anaemia as opposed to our study where the second most common cause is dimorphic anaemia. Chetal Suva et al., (2015), conducted similar study on 50 patients of pancytopenia and their study also found megaloblastic anaemia due to nutritional deficiency to be the most common cause of pancytopenia, ${ }^{5}$ which is similar to the present study. Pinal Shah et al., (2017) in their study on 40 cases of pancytopenia observed megaloblastic anaemia to be the most common cause of pancytopenia ${ }^{6}$ like our study but in contrast to our study, they found aplastic to be the second most common cause.

In a study conducted by Govindraj T. et al., (2011) on 50 patients pancytopenia, the results found were almost equivalent to the present study with the following causes of pancytopenia: ${ }^{7}$

1. Megaloblastic anaemia $-44 \%$

2. Mixed nutritional anaemia $-20 \%$

3. Hypersplenism - $12 \%$

4. Aplastic anaemia $-10 \%$

5. Malignant conditions $-6 \%$

6. Myelodysplastic syndromes $-2 \%$

7. Others $-6 \%$

Following studies conducted in India were in disagreement with the present study:

In a study conducted by Varma N. et al., (1992) on 571 paediatric patients of pancytopenia, aplastic anaemia (40.6\%) was found to be the most common cause while megaloblastic anaemia $(23.26 \%)$ was the second most common cause of pancytopenia in their study. ${ }^{8}$ In another study by Kumar R. et al., (2001) on 166 patients, aplastic anaemia (29.5\%) was found to be the most common cause followed by Megaloblastic anaemia $(22.3 \%) .{ }^{9}$ This may be because of variations in geographical location, nutritional status and prevalence of infections etc.

Although, aplastic anaemia has been found to be the most common cause of pancytopenia in majority of studies across developed parts of the world, however, most of the studies done in developing countries revealed megaloblastic anaemia to be the most common cause. In few of the studies, dimorphic anaemia was found to be the second most common cause. This is explainable by poor nutritional status in these countries. The same is the scenario in Bundelkhand region; poverty and backwardness are responsible for the high prevalence of nutritional deficiency anaemias. Megaloblastic anaemia was found to be the most common cause of pancytopenia in the present study followed by dimorphic anaemia. Combined iron deficiency and vitamin B12 deficiency is especially more prevalent among females of reproductive age group, where, blood loss by menstruation and child birth superadds to the nutritional deficiency. Hypersplenism was the third most common cause of pancytopenia in our study, which is explainable by the endemicity of malaria in Bundelkhand region which is a leading cause of tropical splenomegaly.

\section{CONCLUSIONS}

Bone marrow aspiration is an inexpensive, quick, minimally invasive and very cost effective diagnostic tool in evaluating the aetiology of pancytopenia. In Bundelkhand region, the most common cause of pancytopenia was found to be megaloblastic anaemia followed by dimorphic anaemia which is explainable owing to economic backwardness of this region which is responsible for high prevalence of megaloblastic anaemia and combined nutritional deficiency (dimorphic anaemia) in this region. Tropical splenomegaly, especially due to hyperreactive malarial splenomegaly is quite common. Malaria is endemic in Bundelkhand region, which explains hypersplenism being third most common cause of pancytopenia in our study. Hence, to put succinctly, the present study drew the conclusion that along with detailed clinical examination and complete blood count, bone marrow examination is very useful to diagnose the aetiology of pancytopenia, thereby helping clinician in planning management of these patients.

Data sharing statement provided by the authors is available with the full text of this article at jemds.com.

Financial or other competing interests: None.

Disclosure forms provided by the authors are available with the full text of this article at jemds.com.

\section{REFERENCES}

[1] Tilak V, Jain R. Pancytopenia--a clinico-hematologic analysis of 77 cases. Indian J Pathol Microbiol 1999;42(4):399-404.

[2] Khodke K, Marwah S, Buxi G, et al. Bone marrow examination in cases of pancytopenia. JIACM 2001;2:559.

[3] Kumar V, Abbas A, Aster J, et al. Patologic basis of disease. $10^{\text {th }}$ edn. South Asia Edition 2018. 
[4] Manzoor F, Karandikar MN, Nimbargi RC. Pancytopenia: a clinico-hematological study. Medical Journal of D.Y. Patil Vidyapeeth 2014;7(1):25-8.

[5] Suva DC, Chavada A, Chhotala Y, et al. Study of bone marrow aspiration in cases of pancytopenia, one year study. Indian Journal of Basic and Applied Medical Research 2015;5(1):221-5.

[6] Shah P, Patel RD, Gamit B, et al. Bone marrow examination in cases of pancytopenia. International Journal of Research in Medical Sciences 2017;5(4):1494-8.
[7] Govindraj T. Bone marrow study in adults with pancytopenia. (Doctoral Dissertation) April 2011.

[8] Naseem S, Varma N, Das R, et al. Pediatric patients with bicytopenia/pancytopenia: review of etiologies and clinico-hematological profile at a tertiary center. Indian J Pathol Microbiol 2011;54(1):75-80.

[9] Kumar R, Kalra SP, Kumar H, et al. Pancytopenia--a six year study. J Assoc Physicians India 2001;49:1078-81. 